\title{
Pericarditis, Pleural Effusion, and Pneumonitis with Transient Mitochondrial Antibodies
}

\author{
J. GUARDIA， J. GOMEZ， CARMEN MARTIN， J. M. MARTINEZ-VAZQUEZ, \\ R. BACARDI, J. TORNOS
}

British Medical fournal, 1975, 1, 370-371

25 days on prednisone $15 \mathrm{mg}$ once daily. Follow-up for 16 months showed no recurrence.

\begin{abstract}
Summary
Four women with fever, arthromyalgias, pericarditis, pleural effusion, high erythrocyte sedimentation rates, and lymphopenia had mitochondrial antibodies in the serum in the absence of antinuclear antibody. Their illness lasted 5-12 weeks and the antibody test results became negative on remission. Absence of specific bacteriological findings, normal antistreptolysin $O$ titres, resistance to antibiotics, and good response to steroids suggested that these cases represented a milder and less persistent form of thesyndrome resembling systemic lupus erythematosus described by German authors.
\end{abstract}

\section{Introduction}

Serum mitochondrial antibodies are found mainly in patients with primary biliary cirrhosis (Walker et al., 1965) and related chronic liver diseases (Doniach et al., 1966; Doniach and Walker, 1974). They have also been detected in collagen disorders with (Walker et al., 1970; Whaley et al., 1970) or without (Fulford et al., 1972) subclinical liver involvement. In the general population their prevalence is $0.4-0.7 \%$.

A clinical syndrome resembling systemic lupus erythematosus (S.L.E.) and characterized by the presence of circulating mitochondrial antibodies was described in Germany (Maas and Schubothe, 1973; Berg et al., 1973). We report here four similar cases which differ from those previously described in that the clinical condition went into remission and biochemical abnormalities were transient.

\section{Patients and Methods}

Case 1.-A 34-year-old woman was admitted to hospital with one week's history of fever, myalgia, and arthralgia. She later developed thoracic pain and dyspnoea. Chest $x$-ray examination showed pleural and pericardial effusions. She was treated with salicylates and all signs and symptoms disappeared after 36 days. Eighteen months later she remained healthy.

Case 2.-A 25-year-old woman was seen after a week of fever, chest pain, and dyspnoea. Some relief was obtained with tetracycline but 10 days later the dyspnoea and left thoracic pain reappeared. Pneumonitis, pleural effusion, and pericarditis were confirmed by $x$-ray examination. Pleural biopsy showed inflammatory cells with excess collagen. She required several pleural taps but recovered after

\footnotetext{
Department of Internal Medicine, Ciudad Sanitaria de la Seguridad Social, Barcelona, Spain

J. GUARDIA, M.D., Chief Clinician

J. GOMEZ, M.D., Medical Resident

J. M. MARTINEZ-VAZQUEZ, M.D., Medical Assistant

R. BACARDI, M.D., Chief Assistant

J. TORNOS, M.D., Head of Department

Department of Haematology, Ciudad Sanitaria de la Seguridad

Social, Barcelona, Spain

CARMEN MARTIN, M.D., Chief Clinician
}

Case 3.-A 50-year-old woman was admitted with fever and dyspnoea which had been noticed a month and again 15 days previously. Chest $x$-ray examination showed pericarditis and left pleural effusion which became bilateral within a few days. She was treated with salicylates and recovered after 40 days. Fourteen months later she was well.

Case 4.-A 58-year-old woman was admitted with fever, retrosternal pain, and orthopnoea. She had had vitiligo and occasional joint pains for two years. Pericarditis and bilateral pneumonitis were diagnosed and treatment with antibiotics and prednisone $15 \mathrm{mg}$ once daily was begun. She recovered after one month and was still in remission 18 months later.

Serological Methods.-Autoantibodies were detected by indirect immunofluorescence (I.F.L.) on cryostat sections of rat stomach, liver, and kidney using a fluorescein conjugated antihuman $\lambda$-globulin serum, and titres were established by repeating I.F.L. on serum dilutions. Immunoglobulins and $\mathrm{C} 3$ levels were determined by single radial diffusion with Hyland immunoplates. Serological tests for syphilis (venereal disease research laboratory, Meinicke, Reiter, and complement fixation tests) and other laboratory determinations were done by standard methods.

\section{Results}

Results of investigations are shown in the table. The erythrocyte sedimentation rate (E.S.R. Westergren) was greatly raised in all cases. Total white cell counts were normal but lymphopenia was present in all four patients. Serum electrophoresis showed an increase in $\alpha_{2}$ - and $\beta$-globulins while $\operatorname{IgG}, \operatorname{IgM}, \operatorname{IgA}$, and C3 levels remained persistently normal. Serological tests for syphilis, rheumatoid factors, Paul-Bunnell reactions, and antistreptolysin $O$ (A.S.O) titres gave negative results. Liver function was normal. Bacteriological analysis of pleural fluid and blood cultures showed nothing abnormal, and Mantoux test results were also negative.

Mitochondrial antibodies were present in the acute stage in titres varying from 50 to 200 . Two patients had become negative for mitochondrial antibodies when retested at six months, and in the other two they persisted for at least six weeks and four and a half months, with negative results a year after recovery. Antinuclear (A.N.A.) and smooth muscle antibodies were never found. In our laboratory we found that the general incidence of mitochondrial antibodies was low; out of 1145 mixed hospital patients tested 13 were positive for antibodies in addition to the four patients described. Nine of these patients had primary biliary cirrhosis, two had chronic active hepatitis, one had Sjögren's syndrome, and one had autoimmune haemolytic anaemia.

\section{Discussion}

The clinical manifestations in the four patients suggested a mild collagen disorder. The female sex; presentation with fever, arthralgia, myalgia, pleural effusion, and pericarditis; the high E.S.R. with lymphopenia; the negative bacteriological findings and A.S.O titres; and resistance to antibiotics with good response to steroids are all suggestive features. Classical S.L.E., however, is unlikely in view of the relatively short duration of the illness- 
Clinical and Laboratory Data in Patients with S.L.E.-like Syndrome associated with Mitochondrial Antibodies

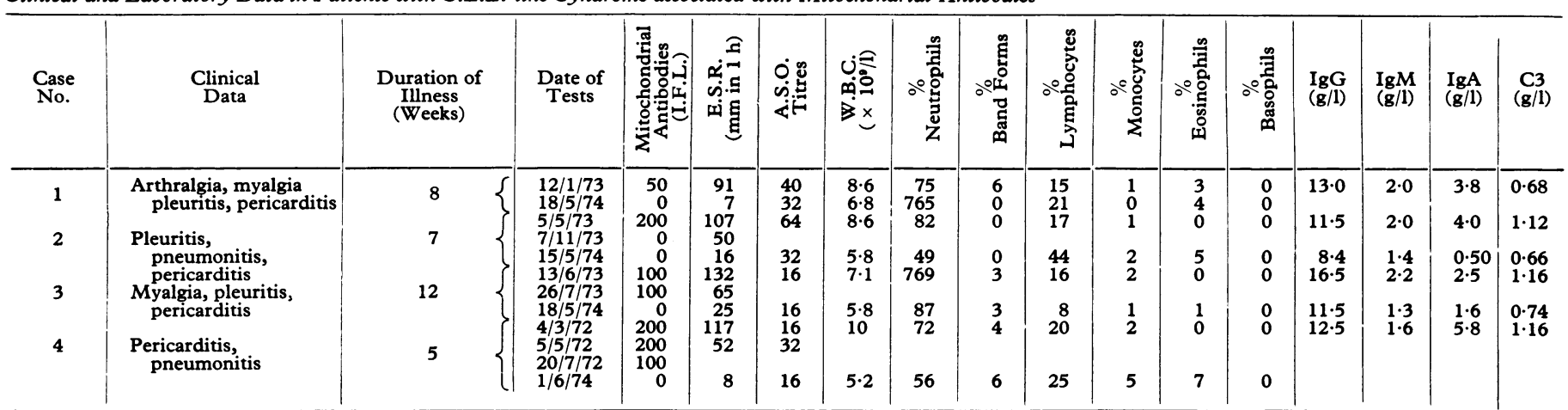

Conversion: SI to Traditional Units-W.B.C.: $1 \times 10^{\circ} / 1=1000 / \mathrm{mm}^{3}$. Immunoglobulins: $1 \mathrm{~g} / 1=100 \mathrm{mg} / 100 \mathrm{ml}$.

5-12 weeks-the normal serum immunoglobulin and complement levels, and the absence of L.E. cells and A.N.A. Mitochondrial antibodies occur in $5-8 \%$ of patients with collagen disorders though not as a rule in typical S.L.E. Some patients with mitochondrial antibodies who were studied had subclinical liver disease with raised alkaline phosphatase levels and periportal lymphoid cell infiltrates on liver biopsy (Walker et al., 1970; Whaley et al., 1970). Others presented with a chronic neurological disorder resembling multiple sclerosis (Fulford et al., 1972). A larger series with a clinical picture suggestive of S.L.E. with mitochondrial antibodies was reported by Maas and Schubothe (1972) and a similar syndrome was observed by Berg et al. (1973). Most patients studied in Germany were women who suffered repeated attacks of fever, arthralgia, and pleural symptoms with a high E.S.R., absent A.N.A., and little evidence of subclinical liver disease. W.B.C. counts tended to be raised in the active phase but several patients had persistent lymphopenia. Mitochondrial antibodies were of high titre-256-16 000-with a tendency to decrease during remissions.

Our four cases seemed to show a similar syndrome, but less severe and less persistent. The mitochondrial antibodies were of lower titres and the test results became negative on remission. The presence of these antibodies in the acute stage and their decrease thereafter suggest a relation with the illness. The I.F.L. could not be attributed to cardiolipin antibodies since tests for syphilis gave negative results (Catterall, 1972). The cause of this new S.L.E.-like syndrome, the stimulus to mitochondrialantibody synthesis, and the long-term outcome of the disease are as yet unknown. It will be of interest to follow patients with repeated antibody tests to see if further clinical exacerbations are preceeded by the reappearance of the antibodies, as occurs in the case of DNA-antibodies in classical S.L.E.

We thank Drs. J. Canals, A. Cadahì, and A. Mirada for allowing us to study patients under their care; Dr. Arcalis for performing the serological tests for syphilis; and Dr. M. T. Gallart for C3 and immunoglobulin estimations.

\section{References}

Berg, P. A., Traunecker, U., and Märker, A. (1973). German Medicine, 3, 58. Catterail, R. D. (1972). British fournal of Venereal Diseases, 48, 1.

Doniach, D., et al. (1966). Clinical Experimental Immunology, 1, 237.

Doniach, D., and Walker, G. (1974). Gut, 15, 664

Fulford, K. W. M., et al. (1972). Brain, 95, 373.

Maas, D., and Schubothe, H. (1972). Deutsche medizinische Wochenschrift, 98, 131.

Walker, J. G., et al. (1965). Lancet, 1, 827.

Walker, J. G., Doniach, D., and Doniach, I. (1970). Quarterly fournal of Medicine, 39, 31.

Whaley, K., et al. (1970). Lancet, 1, 861.

\section{PRELIMINARY COMMUNICATION}

\section{Ultrasound Monitoring of Hepatic Metastases during Chemotherapy}

\author{
E. D. GILBY, K. J. W. TAYLOR
}

British Medical fournal, 1975, 1, 371-373

\section{Summary}

Grey-scale ultrasonography has been found to be the most sensitive method of detecting metastatic disease of

Institute of Cancer Research, Sutton, Surrey

E. D. GILBY, M.B., M.R.C.P., Ludwig Research Fellow

Department of Nuclear Medicine, Royal Marsden Hospital, Sutton, Surrey

K. J. W. TAYLOR, M.B., PH.D., Gordon Jacobs Research Fellow the liver. In two cases the results of chemotherapy were monitored by ultrasound; the response to treatment could be distinguished from non-response and ultrasonography gave useful information when chemotherapy made radioisotope examination unreliable.

\section{Introduction}

The use of chemotherapy for patients with hepatic metastases requires a simple method for monitoring the response. The results of radioisotope methods (scintigraphy) are disappointing since the resolution is poor and uptake of isotope depends on phagocytic function, which may be impaired by chemotherapy. Radiological methods require repeated vascular intrusion, which is especially hazardous in patients suffering from hemostatic defects resulting from thrombocytopenia or extensive liver disease.

Grey-scale ultrasonography offers a simple non-intrusive means of visualizing the normal liver parenchyma and detecting small metastatic deposits which replace the normal anatomy (Taylor and Carpenter, 1974). Serial examinations during 